\title{
High retention membrane bioreactors: challenges and opportunities
}

\section{Revised Critical Review Submitted to Bioresource Technology}

June 2014

Wenhai Luo ${ }^{a}$, Faisal I. Hai ${ }^{a}$, William E. Price ${ }^{b}$, Wenshan Guo ${ }^{c}$, Huu H. Ngo ${ }^{c}$, Kazuo Yamamoto $^{\text {d }}$, Long D. Nghiem ${ }^{a^{*}}$

${ }^{a}$ Strategic Water Infrastructure Laboratory, School of Civil Mining and Environmental Engineering, University of Wollongong, Wollongong, NSW 2522, Australia

${ }^{b}$ Strategic Water Infrastructure Laboratory, School of Chemistry, University of Wollongong, Wollongong, NSW 2522, Australia

${ }^{c}$ Centre for Technology in Water and Wastewater, School of Civil and Environmental Engineering, University of Technology Sydney, Sydney, NSW 2007, Australia

${ }^{d}$ Environmental Science Center, The University of Tokyo, Tokyo 113-0033, Japan

\footnotetext{
* Corresponding author: longn@uow.edu.au; Ph: +61 (2) 42214590.
} 


\begin{abstract}
Extensive research has focussed on the development of novel high retention membrane bioreactor (HR-MBR) systems for wastewater reclamation in recent years. HR-MBR integrates high rejection membrane separation with conventional biological treatment in a single step. High rejection membrane separation processes currently used in HR-MBR applications include nanofiltation, forward osmosis, and membrane distillation. In these HRMBR systems, organic contaminants can be effectively retained, prolonging their retention time in the bioreactor and thus enhancing their biodegradation. Therefore, HR-MBR can offer a reliable and elegant solution to produce high quality effluent. However, there are several technological challenges associated with the development of HR-MBR, including salinity build-up, low permeate flux, and membrane degradation. This paper provides a critical review on these challenges and potential opportunities of HR-MBR for wastewater treatment and water reclamation, and aims to guide and inform future research on HR-MBR for fast commercialisation of this innovative technology.
\end{abstract}

Key words: High retention membrane bioreactor; Trace organic chemicals (TrOCs); Nanofiltration (NF); Membrane distillation (MD); Forward osmosis (FO) 


\section{Introduction}

Water reuse is an important measure to simultaneously address fresh water scarcity and environmental pollution (Shannon et al., 2008; Grant et al., 2012). Safe and reliable water reuse requires adequate removal of salts, nutrients (such as nitrogen and phosphorous), pathogenic agents, and trace organic chemicals (TrOCs) from reclaimed effluent. Amongst these contaminants, the removal of TrOCs is possibly the most challenging aspect as conventional wastewater treatment systems were not specifically designed for their removal (Schwarzenbach et al., 2006). TrOCs are continuously introduced into the sewer via regular household activities and during industrial production. As a result, these TrOCs including pharmaceuticals, personal care products, endocrine disrupting compounds, pesticides and industrial chemicals occur ubiquitously in raw wastewater at concentrations of several $\mu \mathrm{g} / \mathrm{L}$ or below (Ternes et al., 2004; Osorio et al., 2012; Tran et al., 2014). If not adequately removed, many of these TrOCs may have adverse impacts on human health and the ecosystem. For example, some natural human sex hormones can induce endocrine disrupting effect in fish at concentrations as low as $1 \mathrm{ng} / \mathrm{L}$ (Schwarzenbach et al., 2006). Thus, their widespread occurrence in wastewater does not only restrict the reuse of treated effluent, but also cause pollution of water bodies receiving effluent discharge.

Recent decades have seen the maturity of membrane bioreactor (MBR) systems as an alternative wastewater treatment technology that is superior than the conventional activated sludge (CAS) treatment processes (Hai et al., 2014). MBRs integrate low pressure membrane filtration, such as microfiltration (MF) or ultrafiltration (UF), with activated sludge treatment. Compared to CAS processes, MBRs are usually operated at higher biomass concentrations (i.e. 10-20 g/L) and longer sludge retention times (i.e. 10-30 d), resulting in better quality effluent and lower sludge production. For the same treatment capacity, the physical footprint of MBR is also much smaller than that of the CAS process (Hai et al., 2014).

The performance of MBR with respect to TrOC removal has been extensively investigated in recent studies (Tadkaew et al., 2011; Wijekoon et al., 2013; Luo et al., 2014). Tadkaew et al. (2011) reported that, during MBR treatment, hydrophobic TrOCs can adsorb to the biosolids, resulting in longer retention times in the bioreactor, and thereby exhibiting higher removal efficiency than the CAS process. However, some hydrophilic TrOCs such as carbamazepine and diclofenac can be similarly persistent to CAS and MBR treatment. Because TrOCs can freely permeate through MF and UF membranes, the retention time of the hydrophilic and persistent TrOCs in the bioreactor is the same as the hydraulic retention time (HRT). This is 
particularly important as owing to maintenance of higher MLSS concentration, compared to the CAS process, a shorter HRT is usually applied during MBR operation. Thus, the occurrence of hydrophilic and persistent TrOCs in MBR permeate necessitates a posttreatment process to ensure their removal if potable water reuse is intended. The posttreatment process mainly involves reverse osmosis or nanofiltration (Alturki et al., 2010; Nguyen et al., 2013), UV oxidation (Nguyen et al., 2013) or ozonation (Reungoat et al., 2010). While high water quality is achieved after these multiple treatment processes, they can be expensive, energy intensive and, thus can compromise the economics and environmental advantages of water reuse (Shannon et al., 2008).

Further developments of MBR have led to the emergence of a novel high retention (HR)MBR concept. HR-MBR combines biological treatment and high retention membrane separation into a single step. The high retention membrane separation process can effectively retain TrOCs, thus prolonging their retention time in the bioreactor and potentially enhancing their biodegradation. By improving TrOC removal, HR-MBRs can offer a reliable and elegant solution for the production of high quality effluent for potable water reuse or direct effluent discharge in environmental sensitive areas. Not surprisingly, the number of studies dedicated to the development of HR-MBR has increased rapidly in the last few years (Lay et al., 2010; Yap et al., 2012). Given the remaining technological challenges associated with the development of HR-MBR systems, including salinity build-up, low water flux, and membrane stability, many more studies are expected in the near future.

This paper provides a critical review on the challenges and potential opportunities of HRMBR for wastewater treatment and water reclamation. The aim was also to guide and inform future research on HR-MBR to fast track the scale up and commercialization of this innovative technology.

\section{HR-MBR configuration}

Three HR-MBR configurations have been investigated in the literature (Fig. 1). They include nanofiltration membrane bioreactor (NF-MBR) (Choi et al., 2002), membrane distillation bioreactor (MDBR) (Phattaranawik et al., 2008) and osmotic membrane bioreactor (OMBR) (Achilli et al., 2009). In these systems, nanofiltration (NF) or reverse osmosis (RO), membrane distillation (MD) and forward osmosis (FO) are used as the high retention membrane separation process. The key differences between these systems and conventional MBRs are summarised in Table 1. Although all recent studies on HR-MBR (with the 
exception of a study by Chen et al. (2014)) have focused on the coupling of a high retention membrane process with an activated (aerated) biological reactor, an anaerobic reactor could be used to form an anaerobic HR-MBR (AnHR-MBR) system (Fig. 1d). Similar to conventional MBR, the membrane process in both HR-MBR and AnHR-MBR can be designed and operated in either submerged or side-stream modes.

\section{[TABLE 1]}

\section{[FIGURE 1]}

\subsection{Nanofiltration membrane bioreactor}

The configuration of NF-MBR is similar to conventional MBR, but using an NF membrane or low pressure RO membrane (Fig. 1a). Given the similarity between NF and RO processes, hereafter, they will be both referred to as NF. NF membranes can effectively retain low molecular weight organic contaminants, increasing their retention time in the bioreactor for better biological degradation. Although NF is a mature process with a large number of full scale installations, it was not specifically designed for the separation of biomass. Thus, severe membrane fouling can be expected in NF-MBR applications under high hydraulic pressure. One way to reduce this is to operate at a very low permeate flux and a high cross flow velocity to minimise cake layer formation on the membrane surface. With the development of a range of NF membranes that are inexpensive, fouling resistant, chemically stable and highly permeable, the issue of membrane fouling could potentially be resolved in the near future ( $\mathrm{Li}$ and Wang, 2010), allowing for NF-MBR to replace the current treatment train consisting of activated sludge treatment, MF/UF, and subsequently NF, typically used for potable water reuse applications.

\subsection{Osmotic membrane bioreactor}

The OMBR system combines FO with CAS treatment. FO is an osmotically driven membrane process where water transports from a feed solution across a semi-permeable FO membrane, to a draw solution (Cath et al., 2006). Commonly used draw solutes are inorganic salts with low molecular weights such as $\mathrm{NaCl}$ and $\mathrm{MgCl}_{2}$. In a typical OMBR system (Fig. 1b), water is extracted from the mixed liquor into the draw solution by osmosis, with the FO membrane acting as a barrier to solute transport and providing effective rejection of contaminants. In most cases, a draw solute recovery process such as RO or MD is required to reconcentrate the diluted draw solution for continuous operation and to obtain the final product water for beneficial reuse (Fig. 1b). The solute recovery process can also act as an 
extra barrier to residual compounds that could pass through FO membranes, thereby further improving the quality of product water.

FO is still an emerging technology with limited full scale applications. Nevertheless, given its low fouling propensity (Cath et al., 2006), FO can be a good candidate for integration with biological treatment to form a HR-MBR system. In fact, the low fouling propensity of FO during OMBR operation, especially when the active layer of the membranes faces the mixed liquor, has been demonstrated in many studies (Achilli et al., 2009; Zhang et al., 2012b; Zhang et al., 2014). This can be attributed to the absence of a hydraulic pressure and low permeate flux typically associated with this process as well as the smooth surface of the FO membranes (Yap et al., 2012). When a draw solution such as seawater is readily available and the recovery of clean water for recycling is not required, the energy consumption of OMBR can be substantially lower than that of a conventional MBR-RO hybrid system (Cornelissen et al., 2011). Even when RO is required for draw solute recovery, the high retention FO membrane can also protect the RO membrane from fouling, thereby reducing costs for membrane cleaning and replacement. Therefore, OMBR has potential to replace the current hybrid MBR-RO system for water recycling.

\subsection{Membrane distillation bioreactor}

In MDBR, the MD process is utilized to separate high quality product water from the mixed liquor in a thermophilic bioreactor (Fig. 1c). MD is a thermally driven membrane process where only the vapour phase (e.g. water vapour) can be transported through the porous hydrophobic membrane. In theory, all four different MD configurations which have been intensively investigated in the literature including air gap, vacuum, sweep gas and direct contact, can be used for MDBR (Alkhudhiri et al., 2012). However, since MDBR is still in its infancy, most if not all MDBR studies to date have used the direct contact MD configuration which can be readily constructed at the laboratory scale level. In a direct contact MDBR system, the heated mixed liquor and condensate water are circulated on each site of the membrane. The difference in temperature induces a transmembrane vapour pressure differential potential which acts as the driving force for the transport of water vapour through the membrane. The MDBR system is usually operated at atmospheric pressure and at either mesophilic (up to $40{ }^{\circ} \mathrm{C}$ ) or thermophilic $\left(40-60{ }^{\circ} \mathrm{C}\right.$ ) temperature (Khaing et al., 2010). In the MD process, volatile solutes can be transported across the membrane while nonvolatile substances can be completely retained. However, the biological degradation and 
aeration-stripping can contribute to the removal of volatile solutes, allowing MDBR to potentially achieve a high overall removal of almost all organic contaminants (Table 2).

\subsection{Anaerobic HR-MBR system}

A notable variation to most HR-MBR systems investigated in recent years is the combination of a high retention membrane with an anaerobic bioreactor, potentially forming the energy efficient AnHR-MBR system (Fig. 1d). Indeed, AnHR-MBR can produce biogas which can be converted into electricity and heat while its energy consumption mainly derives from biogas sparging for membrane scouring and biomass mixing (Fig. 1d). In addition, the anaerobic process can result in significant reduction in sludge production, thus reducing costs for sludge handling.

Because of the lack of nitrifying and phosphorous accumulating bacteria under anaerobic conditions, AnMBR is not effective for the removal of nutrients (Smith et al., 2012). As a result, ammonia and phosphate can accumulate in the bioreactor. Although no studies have attempted to address this issue, the build-up of ammonium and phosphate during AnHRMBR presents an excellent opportunity for nutrient recovery possibly in the form of struvite (Xie et al., 2014). In addition, given the use of high retention membranes, the accumulation of these nutrients in the bioreactor is not expected to influence the final effluent quality.

\section{Performance of HR-MBR}

\subsection{Organic matter and nutrient removal}

Whilst the development of HR-MBR is on-going, its potential for enhancing contaminant removal has already been demonstrated in a number of studies (Table 2). Total organic carbon removal of over $90 \%$ has been consistently reported for various HR-MBR systems due to the complementarity between membrane rejection and biological degradation. For example, Choi et al. (2007b) reported that the concentration of dissolved organic carbon in the supernatant of an NF-MBR was three times higher than that in the supernatant of a conventional MF-MBR. Such high rejection of organic matter by membranes used in HRMBR can increase their retention time in the bioreactor and therefore facilitate their biological degradation.

Given the high rejection capability of membranes, effective removal of nutrients could be achieved by HR-MBR (Table 2). For example, FO membranes can reject over $99 \%$ of phosphate and $80 \%$ of ammonia during the concentration of sludge centrate from an anaerobic digester (Holloway et al., 2007). In AnHR-MBR, although biological removal of 
nutrients is not effective under anaerobic conditions, they can be greatly retained in the bioreactor by the membrane, thus ensuring high final effluent quality (Chen et al., 2014). However, the accumulation of these retained nutrients, particularly ammonia, may exert toxic effects on microorganisms in the bioreactor. Therefore, as discussed in section 2.4, there exists an opportunity to recover these nutrients during AnHR-MBR treatment.

\section{[TABLE 2]}

\subsection{Trace organic chemicals removal}

NF, MD and FO can achieve excellent rejection of most TrOCs (Table 3). In general, hydrophilic or charged organic compounds with molecular weight of higher than $200 \mathrm{~g} / \mathrm{mol}$ can be effectively rejected by NF and FO membranes mainly via size exclusion, electrostatic exclusion and adsorption to membranes (Nghiem et al., 2004; Xie et al., 2012). It is noteworthy that because hydrophobic TrOCs can partition into polymeric membrane and subsequently diffuse through the membrane, their removal by NF would be lower than expected solely based on size exclusion mechanisms (Nghiem et al., 2004). However, hydrophobic TrOCs can readily adsorb onto activated sludge, which prolongs their retention in the bioreactor and can lead to enhanced biodegradation (Cirja et al., 2008). In a similar way, the longer retention of hydrophilic TrOCs in the bioreactor by a high retention membrane process may also enhance their biological removal.

\section{[TABLE 3]}

The high removal of TrOCs by HR-MBR has been demonstrated in recent studies. Lay et al. (2012) reported over $96 \%$ removal of 5 pharmaceuticals by a novel OMBR system. This result was in consistent to a study by Alturki et al. (2012) who investigated the removal of 50 TrOCs by OMBR and reported over $80 \%$ removal efficiency for compounds with molecular weight of larger than $266 \mathrm{~g} / \mathrm{mol}$. They also reported that the removal efficiencies of TrOCs with molecular weight of less than $266 \mathrm{~g} / \mathrm{mol}$ were governed largely by their biodegradability (Alturki et al., 2012). Wijekoon et al. (2014a) reported over 95\% removal of 30 TrOCs with various physicochemical properties by MDBR treatment. It was also revealed that the removal efficiencies of TrOCs by MDBR were not significantly affected by the thermophilic condition and salinity build-up in the bioreactor (Wijekoon et al., 2014a). Further studies are still expected to elucidate the mechanisms for TrOC removal and the associated influencing factors.

\section{Key challenges for further developments of HR-MBRs}


Although the potential of HR-MBR for wastewater treatment and water reclamation has been recently demonstrated (Choi et al., 2006; Achilli et al., 2009; Khaing et al., 2010), there remain several technological challenges, mainly related to the build-up of salinity in the bioreactor, low water flux and membrane degradation (Fig. 2). Addressing these is the key for further development of HR-MBR technologies. Undoubtedly, these challenges will motivate many future dedicated scientific investigations.

[FIGURE 2]

\subsection{Salinity build-up}

The membranes used in HR-MBRs can effectively retain inorganic substances (i.e. salts), colloidal and dissolved solids. This ensures the production of high quality effluent, but also results in the build-up of salinity in the bioreactor. The build-up of salinity presents several problems for the application of HR-MBR (Fig. 2). Recent research has indicated that increasing salt concentration in the bioreactor could greatly affect physical and biochemical properties of activated sludge (Qiu and Ting, 2014; Tan et al., 2014). For example, it could increase the concentration of soluble microbial products (SMP) and extracellular polymeric substances (EPS) in the bioreactor (Qiu and Ting, 2014). The high concentration of SMP and EPS could yield unfavourable physicochemical conditions for oxygen transfer and fluid rheology as well as accelerate membrane fouling by increasing pore block resistance (Lay et al., 2010). Salinity build-up can also alter the microbial community, slow down microbial kinetics and even inhibit microbial growth in the bioreactor (Nawaz et al., 2013; Qiu and Ting, 2013).

The concentration factor $(\mathrm{CF})$, which is defined as the degree that salt concentration increases in the bioreactor, is an important parameter for controlling and optimising the build-up of salinity in HR-MBRs (Lay et al., 2010). CF is directly related to the ratio of SRT to HRT during HR-MBR operation (Phattaranawik et al., 2008; Lay et al., 2010). High CF values could achieve desirable water recovery, but also result in the build-up of salinity in the bioreactor, owing to the accumulation of rejected inorganic salts. Thus, an optimum CF value should be identified for balancing water recovery targets and salt accumulation in the bioreactor. Lay et al. (2010) suggested that optimum CF values for HR-MBR could be in the range of 10-30, corresponding to a total dissolved solids (TDS) concentration of between 5 and $15 \mathrm{~g} / \mathrm{L}$ in the bioreactor, for a typical wastewater with TDS of $500 \mathrm{mg} / \mathrm{L}$. This possible range was determined based on the typical SRT and HRT of conventional MBRs at 10-30 d 
and lower than $1 \mathrm{~d}$, respectively. However, further research is warranted to establish the fundamental basis for optimizing $\mathrm{CF}$ and delineating the various associated effects.

The build-up of salinity can be reduced by regular sludge withdrawal. However, this reduces the operating SRT of HR-MBR and increases costs for sludge disposal. Moreover, even if an OMBR is operated at an SRT of $10 \mathrm{~d}$, high and stable salinity could still occur in the bioreactor, thus negatively affecting microbial activity and diversity (Qiu and Ting, 2013; Wang et al., 2014). Microbial acclimation and the inoculation of halophilic microorganisms have been suggested as feasible strategies to ensure biological treatment in the high saline environment. Microorganisms involved in CAS are generally non-halophilic, but can tolerate salt concentrations of up to $15 \mathrm{~g} / \mathrm{L} \mathrm{NaCl}$ (Tadkaew et al., 2013). On the other hand, marine or slightly halophilic microorganisms can survive at salt concentration of up to $30 \mathrm{~g} / \mathrm{L} \mathrm{NaCl}$ (Lay et al., 2010). Indeed, numerous studies have demonstrated the effective treatment of hypersaline wastewater by inoculating halophilic microorganisms in conventional biological processes (Table 4).

\section{[TABLE 4]}

The build-up of salinity could be more severe for OMBR due to the diffusion of the draw solute across the FO membrane into the mixed liquor, that is, reverse salt flux (Yong et al., 2012). Therefore, the selection of draw solutes with low diffusivity such as $\mathrm{MgCl}_{2}$ is critical to mitigate salinity build-up in OMBR. An innovative approach to alleviate this issue is the use of organic based draw solutes (Hau et al., 2014). An organic based draw solute is referred to as an organic acid (anion) combined with an organic or an inorganic base (cation)

(Bowden et al., 2012). The reverse salt flux of organic based draw solutes is significantly less than that of their inorganic counterparts (Bowden et al., 2012; Nawaz et al., 2013). More importantly, organic based draw solutes are biodegradable and do not contribute toward salinity build-up in the bioreactor.

\subsection{Low permeate flux}

The permeate fluxes of conventional MBRs are typically in the range of $10-150 \mathrm{~L} / \mathrm{m}^{2} \mathrm{~h}$, depending on operating conditions and membrane configuration (Judd, 2010). However, the permeate fluxes of HR-MBRs demonstrated in recent studies were lower than $10 \mathrm{~L} / \mathrm{m}^{2} \mathrm{~h}$ (Table 1). For example, the highest constant flux was only $9 \mathrm{~L} / \mathrm{m}^{2} \mathrm{~h}$ for an OMBR system using a cellulose triacetate FO membrane (Achilli et al., 2009), whereas the permeate flux of a cellulose acetate NF-MBR system was below $0.042 \mathrm{~L} / \mathrm{m}^{2} \mathrm{~h}$ or equivalent to $0.5 \mathrm{~L} / \mathrm{m}^{2} \mathrm{~h}$ bar 
(Choi et al., 2007a). Thus, HR-MBR requires a large membrane area to obtain a practical water production. This can undoubtedly increase membranes investment and costs for their maintenance or replacement (Fig. 2).

The permeate flux of HR-MBR is directly related to the driving force across the membrane. In the OMBR system, driving force is provided by osmotic pressure differential across FO membrane, which is determined by the concentration of draw solution. In theory, a highly concentrated draw solution can increase the transmembrane driving force for water diffusion (Qin et al., 2010). For example, the pure permeate flux of a FO process could increase from 5 to $12 \mathrm{~L} / \mathrm{m}^{2} \mathrm{~h}$ with the concentration of the draw solution rising from 0.5 to $1.5 \mathrm{M} \mathrm{NaCl}$ (Alturki et al., 2012). However, because of the effects of internal concentration polarization (Cath et al., 2006), no increase in permeate flux was observed beyond this concentration range (Alturki et al., 2012). Moreover, a high concentration of draw solution could also increase the reverse salt flux, exacerbating the build-up of salinity in the feed solution and thus reducing the net transmembrane driving force (Xiao et al., 2011; Kim, 2014).

In the MDBR system, the driving force for water transport could be increased by enhancing the temperature gap across the membrane. Permeate fluxes of $2-15 \mathrm{~L} / \mathrm{m}^{2} \mathrm{~h}$ could be achieved for MDBR with operating temperatures in the range of $30-80{ }^{\circ} \mathrm{C}$ (Phattaranawik et al., 2008). However, elevated temperatures could exacerbate temperature polarization, which in turn compromises the net transmembrane driving force. Moreover, severe membrane scaling under high temperature conditions could increase the membrane resistance and therefore result in flux decline. However, since an elevated temperature can decrease the viscosity of mixed liquor, the diffusion coefficient of water through the membrane in OMBR and NFMBR can be increased, thus enhancing the permeate flux to some extent. For example, the pure permeate flux of a FO process could be increased by $2.4 \%$ per ${ }^{\circ} \mathrm{C}$ in the temperatures range of $16-20^{\circ} \mathrm{C}$ (Cornelissen et al., 2008).

By combing with an anaerobic process, AnHR-MBR could be potentially operated at mesophilic or even thermophilic temperatures without extra heating elements. The anaerobic digestion of wastewater with COD concentrations higher than 4-5 g/L could generate sufficient biogas to heat an AnMBR system up to $35^{\circ} \mathrm{C}$ (Martin et al., 2011). Given that the high temperature enhances water diffusion across the membrane, AnHR-MBR could potentially have higher permeate fluxes in comparison to their aerobic counterparts. However, the low flocculation of anaerobic sludge and the high sludge concentration for anaerobic operation can exacerbate membrane fouling (Smith et al., 2012). As a result, 
frequent membrane cleaning or interval operation seems necessary to sustain the permeate flux of AnHR-MBR.

Recent years have witnessed a remarkable progress in the development of high water permeability and low fouling membranes for NF, FO, and MD applications. For example, the water flux of a novel thin film composite NF membrane that was created based on a UF membrane grafted with poly(oxyethylenemethacrylate) could be 10 times higher than that of cellulose acetate NF membranes (Asatekin et al., 2009). The water permeability of a composite NF membrane could also be significantly improved by introducing zwitterionic groups into the membrane (Ji et al., 2012). In addition, the high water permeability of novel FO membranes, such as a nanoporous polyethersulfone flat sheet FO membrane (Yu et al., 2011), has also been widely fabricated, though limited types of FO membranes are available in the market. However, the suitability of these membranes for HR-MBR still needs to be evaluated in future studies.

\subsection{Membrane stability}

Chemically and biologically stable polymeric materials can be used for MD applications as long as they are hydrophobic and can form micro pores. Examples of these polymeric materials include polytetrafluoroethylene, polyvinylidenefluoride, and polypropylene (Alkhudhiri et al., 2012). Thus, membrane degradation during MDBR operation due to exposure to the biologically active mixed liquor of the bioreactor and aggressive chemical cleaning reagents is unlikely. By contrast, both NF and FO membranes are almost exclusively fabricated on either cellulose or polyamide, thus, membrane stability is a key issue for further development of NF-MBR and OMBR.

The cellulose membranes are easily wetted, promoting high permeability and reducing the risk of the drying out of membranes under air flushing conditions (Judd, 2010). More importantly, the cellulose membranes are much hydrophilic and can mitigate the formation of fouling layer on the membrane surface. However, in a previous study, the biological degradation and hydrolysis of a cellulose acetate membrane used in an NF-MBR system was observed after 250 days of continuous operation (Choi et al., 2007a). The changes of key membrane properties, including pore size, porosity, surface charge and hydrophobicity, led to the deterioration of final effluent quality.

Whilst polyamide membranes can be sufficiently robust to resist biological degradation and hydrolysis of membrane materials in wastewater, they have higher fouling propensity 
compared to cellulose membranes (Judd, 2010). Compared to the application of membranes for water purification, membrane fouling could be more onerous in HR-MBR due to the high organic and inorganic loads of wastewater and the presence of activated sludge with high concentrations of SMP and EPS under salinity build-up conditions. As a result, periodic physical and/or chemical cleaning are required to restore permeate flux. However, cellulose and especially polyamide membranes are susceptible to chemical degradation. For example, the exposure of polyamide membrane to very low concentration of chlorine could result in the structural changes within the polyamide skin layer, thus compromising the membrane performance (Simon et al., 2009).

Because membrane degradation could negatively impact the product water quality, it is essential to understand long term membrane stability and develop techniques to prevent biological and chemical degradation of NF and FO membranes for HR-MBR applications. Fabricating biologically and chemically resistant materials could be a promising approach to overcome the issue of membrane degradation during long term HR-MBR operation. Appropriate module configuration that allows for intermittent introduction of antibacterial reagent to the membrane surface is another approach to prevent biological deterioration of the membranes (Choi et al., 2002).

\section{Future outlook}

The technical feasibility of HR-MBRs has been conclusively demonstrated. However, their practical realisation for wastewater treatment and water reclamation remains an uncertainty and will largely depend on future research to address the above mentioned challenges to make these processes economically viable. Current research on HR-MBR is confined exclusively on to laboratory-scale experiments. Thus, a logical evolution is to demonstrate the potential of HR-MBR at pilot and subsequently full scale level. Although AnHR-MBR has been scarcely studied in the literature, given its potential for simultaneous wastewater treatment, biogas production, and nutrient recovery, this process is likely to be the priority to be implemented at pilot and full scale level.

\section{Conclusion}

Recent research efforts have resulted in the emergence of HR-MBR, which represents the next generation of wastewater treatment technology. HR-MBR can potentially replace the train of multiple treatment processes currently used for water recycling applications.

Nevertheless, there remain several major challenges before practical applications of HR- 
MBR can be realised. These include salinity build-up in the bioreactor, low permeate flux, and membrane degradation. Several innovative approaches can potentially be employed to address these challenges as outlined in this review. Further developments in membrane materials and microbial selection techniques will also be important factors for the future applications of HR-MBR.

\section{Acknowledgement}

This research was supported under Australian Research Council's Discovery Project funding scheme (project DP140103864). The authors would like to thank the Chinese Scholarship Council and the University of Wollongong for the PhD scholarship support to Wenhai Luo.

\section{Reference}

1. Abou Elela, S.I., Kamel, M.M., Fawzy, M.E., 2010. Biological treatment of saline wastewater using a salt-tolerant microorganism. Desalination 250, 1-5.

2. Achilli, A., Cath, T.Y., Marchand, E.A., Childress, A.E., 2009. The forward osmosis membrane bioreactor: A low fouling alternative to MBR processes. Desalination 239, 1021.

3. Alkhudhiri, A., Darwish, N., Hilal, N., 2012. Membrane distillation: A comprehensive review. Desalination 287, 2-18.

4. Alturki, A., McDonald, J., Khan, S.J., Hai, F.I., Price, W.E., Nghiem, L.D., 2012.

Performance of a novel osmotic membrane bioreactor (OMBR) system: flux stability and removal of trace organics. Bioresour. Technol. 113, 201-206.

5. Alturki, A.A., McDonald, J.A., Khan, S.J., Price, W.E., Nghiem, L.D., Elimelech, M., 2013. Removal of trace organic contaminants by the forward osmosis process. Sep. Purif. Technol. 103, 258-266.

6. Alturki, A.A., Tadkaew, N., McDonald, J.A., Khan, S.J., Price, W.E., Nghiem, L.D., 2010. Combining MBR and NF/RO membrane filtration for the removal of trace organics in indirect potable water reuse applications. J. Membr. Sci. 365, 206-215.

7. Alvaro, A.G., Beaucourt, N., Garcia, S.M., 2009. Biological treatment of hypersaline wastewater from meat industry by using halophilic bacterial strains. New Biotechnol. 25, 231-231.

8. Asatekin, A., Olivetti, E.A., Mayes, A.M., 2009. Fouling resistant, high flux nanofiltration membranes from polyacrylonitrile- graft-poly(ethylene oxide). J. Membr. Sci. 332, 6-12. 
9. Bowden, K.S., Achilli, A., Childress, A.E., 2012. Organic ionic salt draw solutions for osmotic membrane bioreactors. Bioresour. Technol. 122, 207-216.

10. Cath, T.Y., Childress, A.E., Elimelech, M., 2006. Forward osmosis: Principles, applications, and recent developments. J. Membr. Sci. 281, 70-87.

11. Chen, L., Gu, Y., Cao, C., Zhang, J., Ng, J.W., Tang, C., 2014. Performance of a submerged anaerobic membrane bioreactor with forward osmosis membrane for lowstrength wastewater treatment. Water Res. 50, 114-123.

12. Choi, J.H., Dockko, S., Fukushi, K., Yamamoto, K., 2002. A novel application of a submerged nanofiltration membrane bioreactor (NF MBR) for wastewater treatment. Desalination 146, 413-420.

13. Choi, J.H., Fukushi, K., Ng, H.Y., Yamamoto, K., 2006. Evaluation of a long-term operation of a submerged nanofiltration membrane bioreactor (NF MBR) for advanced wastewater treatment. Wate Sci. and Tech. 53, 131-136.

14. Choi, J.H., Fukushi, K., Yamamoto, K., 2007a. A submerged nanofiltration membrane bioreactor for domestic wastewater treatment: the performance of cellulose acetate nanofiltration membranes for long-term operation. Sep. Purif. Technol. 52, 470-477.

15. Choi, J.H., Lee, S.H., Fukushi, K., Yamamoto, K., 2007b. Comparison of sludge characteristics and PCR-DGGE based microbial diversity of nanofiltration and microfiltration membrane bioreactors. Chemosphere 67, 1543-1550.

16. Cirja, M., Ivashechkin, P., Schäffer, A., Corvini, P.F.X., 2008. Factors affecting the removal of organic micropollutants from wastewater in conventional treatment plants (CTP) and membrane bioreactors (MBR). Rev. Environ. Sci. Biotechnol. 7, 61-78.

17. Cornelissen, E.R., Harmsen, D., Beerendonk, E.F., Qin, J.J., Oo, H., de Korte, K.F., Kappelhof, J.W.M.N., 2011. The innovative osmotic membrane bioreactor (OMBR) for reuse of wastewater. Water Sci. Technol. 63, 1557-1565.

18. Cornelissen, E.R., Harmsen, D., de Korte, K.F., Ruiken, C.J., Qin, J.J., Oo, H., Wessels, L.P., 2008. Membrane fouling and process performance of forward osmosis membranes on activated sludge. J. Membr. Sci. 319, 158-168.

19. Goh, S., Zhang, J., Liu, Y., Fane, A.G., 2013. Fouling and wetting in membrane distillation (MD) and MD-bioreactor (MDBR) for wastewater reclamation. Desalination $323,39-47$.

20. Grant, S.B., Ambrose, R.F., Deletic, A., Brown, R., Jiang, S.C., Rosso, D., Cooper, W.J., Marusic, I., Saphores, J.D., Feldman, D.L., Hamilton, A.J., Fletcher, T.D., Cook, P.L.M., Stewardson, M., Sanders, B.F., Levin, L.A., 2012. Taking the "waste" out of 
"wastewater" for human water security and ecosystem sustainability. Science 337, 681686.

21. Hai, F.I., Yamamoto, K., Lee, C.H. 2014. Membrane Biological Reactors: Theory, Modeling, Design, Management and Applications to Wastewater Reuse. IWA Publishing, London.

22. Hau, N.T., Chen, S.S., Nguyen, N.C., Huang, K.Z., Ngo, H.H., Guo, W., 2014. Exploration of EDTA sodium salt as novel draw solution in forward osmosis process for dewatering of high nutrient sludge. J. Membr. Sci. 455, 305-311.

23. Holloway, R.W., Childress, A.E., Dennett, K.E., Cath, T.Y., 2007. Forward osmosis for concentration of anaerobic digester centrate. Water Res. 41, 4005-4014.

24. Ji, Y.L., An, Q.F., Zhao, Q., Sun, W.D., Lee, K.R., Chen, H.L., Gao, C.J., 2012. Novel composite nanofiltration membranes containing zwitterions with high permeate flux and improved anti-fouling performance. J. Membr. Sci. 390-391, 243-253.

25. Judd, S. 2010. MBR Book: Principles and Applications of Membrane Bioreactors for Water and Wastewater Treatment (2nd Edition). Elsevier Science, Burlington.

26. Khaing, T.H., Li, J., Li, Y., Wai, N., Wong, F.S., 2010. Feasibility study on petrochemical wastewater treatment and reuse using a novel submerged membrane distillation bioreactor. Sep. Purif. Technol. 74, 138-143.

27. Kim, S., 2014. Scale-up of osmotic membrane bioreactors by modeling salt accumulation and draw solution dilution using hollow-fiber membrane characteristics and operation conditions. Bioresour. Technol. doi: http://dx.doi.org/10.1016/j.biortech.2014.03.101.

28. Kimura, K., Amy, G., Drewes, J.E., Heberer, T., Kim, T.U., Watanabe, Y., 2003. Rejection of organic micropollutants (disinfection by-products, endocrine disrupting compounds, and pharmaceutically active compounds) by NF/RO membranes. J. Membr. Sci. 227, 113-121.

29. Kootenaei, F.G., Ramezani, M., Aminirad, H., Ahmadi, S., Kh, P., Fallahnejad, M., 2014. Comparison in reduction of solids, turbidity and EC between nanofiltration membrane bioreactor and activated sludge. Int. J. Nano Dimens. 5, 21.

30. Kubo, M., Hiroe, J., Murakami, M., Fukami, H., Tachiki, T., 2001. Treament of hypersaline-containing wastewater with salt-tolerant microorganisms. J. Biosci. Bioeng. 91, 222-224.

31. Lay, W.C.L., Liu, Y., Fane, A.G., 2010. Impacts of salinity on the performance of high retention membrane bioreactors for water reclamation: A review. Water Res. 44, 21-40. 
32. Lay, W.C.L., Zhang, Q., Zhang, J., McDougald, D., Tang, C., Wang, R., Liu, Y., Fane, A.G., 2012. Effect of pharmaceuticals on the performance of a novel osmotic membrane bioreactor (OMBR). Sep. Purif. Technol. 47, 543-554.

33. Lay, W.C.L., Zhang, Q., Zhang, J., McDougald, D., Tang, C., Wang, R., Liu, Y., Fane, A.G., 2011. Study of integration of forward osmosis and biological process: Membrane performance under elevated salt environment. Desalination 283, 123-130.

34. Lefebvre, O., Vasudevan, N., Torrijos, M., Thanasekaran, K., Moletta, R., 2005.

Halophilic biological treatment of tannery soak liquor in a sequencing batch reactor.

Water Res. 39, 1471-1480.

35. Li, D., Wang, H., 2010. Recent developments in reverse osmosis desalination membranes. J. Membr. Sci. 20, 4551-4566.

36. Luo, Y.L., Guo, W.S., Ngo, H.H., Nghiem, L.D., Hai, F.I., Kang, J., Xia, S., Zhang, Z.Q., Price, W.E., 2014. Removal and fate of micropollutants in a sponge-based moving bed bioreactor. Bioresour. Technol. 159, 311-319.

37. Martin, I., Pidou, M., Soares, A., Judd, S., Jefferson, B., 2011. Modelling the energy demands of aerobic and anaerobic membrane bioreactors for wastewater treatment. Environ. Technol. 32, 921-932.

38. Nawaz, M.S., Gadelha, G., Khan, S.J., Hankins, N., 2013. Microbial toxicity effects of reverse transported draw solute in the forward osmosis membrane bioreactor (FO-MBR). J. Membr. Sci. 429, 323-329.

39. Nghiem, L.D., Hawkes, S., 2007. Effects of membrane fouling on the nanofiltration of pharmaceutically active compounds (PhACs): Mechanisms and role of membrane pore size. Sep. Purif. Technol. 57, 176-184.

40. Nghiem, L.D., Manis, A., Soldenhoff, K., Schäfer, A.I., 2004. Estrogenic hormone removal from wastewater using NF/RO membranes. J. Membr. Sci. 242, 37-45.

41. Nguyen, L.N., Hai, F.I., Kang, J., Price, W.E., Nghiem, L.D., 2013. Removal of emerging trace organic contaminants by MBR-based hybrid treatment processes. Int. Biodeterior. Biodegrad. 85, 474-482.

42. Osorio, V., Marcé, R., Pérez, S., Ginebreda, A., Cortina, J.L., Barceló, D., 2012. Occurrence and modeling of pharmaceuticals on a sewage-impacted Mediterranean river and their dynamics under different hydrological conditions. Sci. Total Environ. 440, 3-13.

43. Phattaranawik, J., Fane, A.G., Pasquier, A.C.S., Bing, W., 2008. A novel membrane bioreactor based on membrane distillation. Desalination 223, 386-395. 
44. Phattaranawik, J., Fane, A.G., Pasquier, A.C.S., Bing, W., Wong, F.S., 2009.

Experimental study and design of a submerged membrane distillation bioreactor. Chem. Eng. Technol. 32, 38-44.

45. Qin, J.J., Kekre, K.A., Oo, M.H., Tao, G., Lay, C.L., Lew, C.H., Cornelissen, E.R., Ruiken, C.J., 2010. Preliminary study of osmotic membrane bioreactor: effects of draw solution on water flux and air scouring on fouling. Water Sci. Technol. 62, 1353-1360.

46. Qiu, G., Ting, Y.P., 2013. Osmotic membrane bioreactor for wastewater treatment and the effect of salt accumulation on system performance and microbial community dynamics. Bioresour. Technol. 150, 287-297.

47. Qiu, G.L., Ting, Y.P., 2014. Short-term fouling propensity and flux behavior in an osmotic membrane bioreactor for wastewater treatment. Desalination 332, 91-99.

48. Reungoat, J., Macova, M., Escher, B.I., Carswell, S., Mueller, J.F., Keller, J., 2010. Removal of micropollutants and reduction of biological activity in a full scale reclamation plant using ozonation and activated carbon filtration. Water Res. 44, 625-637.

49. Schwarzenbach, R.P., Escher, B.I., Fenner, K., Hofstetter, T.B., Johnson, C.A., von Gunten, U., Wehrli, B., 2006. The challenge of micropollutants in aquatic systems. Science 313, 1072-1077.

50. Shannon, M.A., Bohn, P.W., Elimelech, M., Georgiadis, J.G., Mariñas, B.J., Mayes, A.M., 2008. Science and technology for water purification in the coming decades. Nature 452, 301-310.

51. Sharghi, E.A., Bonakdarpour, B., 2013. The study of organic removal efficiency and halophilic bacterial mixed liquor characteristics in a membrane bioreactor treating hypersaline produced water at varying organic loading rates. Bioresour. Technol. 149, 486-495.

52. Shi, K., Zhou, W., Zhao, H., Zhang, Y., 2012. Performance of halophilic marine bacteria inocula on nutrient removal from hypersaline wastewater in an intermittently aerated biological filter. Bioresour. Technol. 113, 280-287.

53. Simon, A., Nghiem, L.D., Le Clech, P., Khan, S.J., Drewes, J.E., 2009. Effects of membrane degradation on the removal of pharmaceutically active compounds (PhACs) by NF/RO filtration processes. J. Membr. Sci. 340, 16-25.

54. Smith, A.L., Stadler, L.B., Love, N.G., Skerlos, S.J., Raskin, L., 2012. Perspectives on anaerobic membrane bioreactor treatment of domestic wastewater: a critical review. Bioresour. Technol. 122, 149-159. 
55. Tadkaew, N., Hai, F.I., McDonald, J.A., Khan, S.J., Nghiem, L.D., 2011. Removal of trace organics by MBR treatment: The role of molecular properties. Water Res. 45, 24392451.

56. Tadkaew, N., McDonald, J., Khan, S.J., Nghiem, L.D., 2013. Effects of salinity on the removal of trace organic contaminants by membrane bioreactor treatment for water reuse. Desalin. Water Treat. 51, 5164-5171.

57. Tan, J.M., Qiu, G.L., Ting, Y.P., 2014. Osmotic membrane bioreactor (OMBR) for municipal wastewater treatment and the effects of silver nanoparticles on system performance. J. Cleaner Prod. doi: http://dx.doi.org/10.1016/j.jclepro.2014.03.037.

58. Ternes, T.A., Joss, A., Siegrist, H., 2004. Scrutinizing pharmaceuticals and personal care products in wastewater treatment. Environ. Sci. Technol. 38, 392-399.

59. Tran, N.H., Urase, T., Ta, T.T., 2014. A preliminary study on the occurrence of pharmaceutically active compounds in hospital wastewater and surface water in Hanoi, Vietnam. Clean - Soil, Air, Water 42, 267-275.

60. Valladares Linares, R., Yangali Quintanilla, V., Li, Z., Amy, G., 2011. Rejection of micropollutants by clean and fouled forward osmosis membrane. Water Res. 45, 67376744.

61. Wang, X.H., Chen, Y., Yuan, B., Li, X.F., Ren, Y.P., 2014. Impacts of sludge retention time on sludge characteristics and membrane fouling in a submerged osmotic membrane bioreactor. Bioresour. Technol. 161, 340-347.

62. Wijekoon, K.C., Hai, F.I., Kang, J., Price, W.E., Guo, W., Ngo, H.H., Cath, T.Y., Nghiem, L.D., 2014a. A novel membrane distillation-thermophilic bioreactor system: Biological stability and trace organic compound removal. Bioresour. Technol. 159, 334341.

63. Wijekoon, K.C., Hai, F.I., Kang, J., Price, W.E., Guo, W., Ngo, H.H., Nghiem, L.D., 2013. The fate of pharmaceuticals, steroid hormones, phytoestrogens, UV-filters and pesticides during MBR treatment. Bioresour. Technol. 144, 247-254.

64. Wijekoon, K.C., Hai, F.I., Kang, J.G., Price, W.E., Cath, T.Y., Nghiem, L.D., 2014b. Rejection and fate of trace organic compounds (TrOCs) during membrane distillation. J. Membr. Sci. 453, 636-642.

65. Xiao, D., Tang, C.Y., Zhang, J., Lay, W.C.L., Wang, R., Fane, A.G., 2011. Modeling salt accumulation in osmotic membrane bioreactors: Implications for FO membrane selection and system operation. J. Membr. Sci. 366, 314-324. 
66. Xie, M., Nghiem, L.D., Price, W.E., Elimelech, M., 2012. Comparison of the removal of hydrophobic trace organic contaminants by forward osmosis and reverse osmosis. Water Res. 46, 2683-2692.

67. Xie, M., Nghiem, L.D., Price, W.E., Elimelech, M., 2014. Toward resource recovery from wastewater: phosphorus extraction from digested sludge using hybrid forward osmosis - membrane distillation process. Environ. Sci. Technol. Lett. 1, 191-195.

68. Yap, W.J., Zhang, J., Lay, W.C.L., Cao, B., Fane, A.G., Liu, Y., 2012. State of the art of osmotic membrane bioreactors for water reclamation. Bioresour. Technol. 122, 217-222.

69. Yong, J.S., Phillip, W.A., Elimelech, M., 2012. Coupled reverse draw solute permeation and water flux in forward osmosis with neutral draw solutes. J. Membr. Sci. 392-393, 917.

70. Yoon, Y., Westerhoff, P., Snyder, S.A., Wert, E.C., Yoon, J., 2007. Removal of endocrine disrupting compounds and pharmaceuticals by nanofiltration and ultrafiltration membranes. Desalination 202, 16-23.

71. Yu, Y., Seo, S., Kim, I.C., Lee, S., 2011. Nanoporous polyethersulfone (PES) membrane with enhanced flux applied in forward osmosis process. J. Membr. Sci. 375, 63-68.

72. Zaviska, F., Drogui, P., Grasmick, A., Azais, A., Héran, M., 2013. Nanofiltration membrane bioreactor for removing pharmaceutical compounds. J. Membr. Sci. 429, 121 129.

73. Zhang, H.M., Ma, Y.J., Jiang, T., Zhang, G.Y., Yang, F.L., 2012a. Influence of activated sludge properties on flux behavior in osmosis membrane bioreactor (OMBR). J. Membr. Sci. 390, 270-276.

74. Zhang, J., Loong, W.L.C., Chou, S., Tang, C., Wang, R., Fane, A.G., 2012b. Membrane biofouling and scaling in forward osmosis membrane bioreactor. J. Membr. Sci. 403-404, $8-14$.

75. Zhang, Q., Jie, Y.W., Loong, W.L.C., Zhang, J., Fane, A.G., Kjelleberg, S., Rice, S.A., McDougald, D., 2014. Characterization of biofouling in a lab-scale forward osmosis membrane bioreactor (FOMBR). Water Res. 58, 141-151. 


\section{LIST OF FIGURE CAPTIONS}

Fig. 1: Schematic diagram of submerged HR-MBR systems: (a) NF-MBR, (b) OMBR, (c) MDBR, and (d) AnHR-MBR system.

Fig. 2: Technological challenges to further HR-MBR development. 


\section{LIST OF FIGURES}

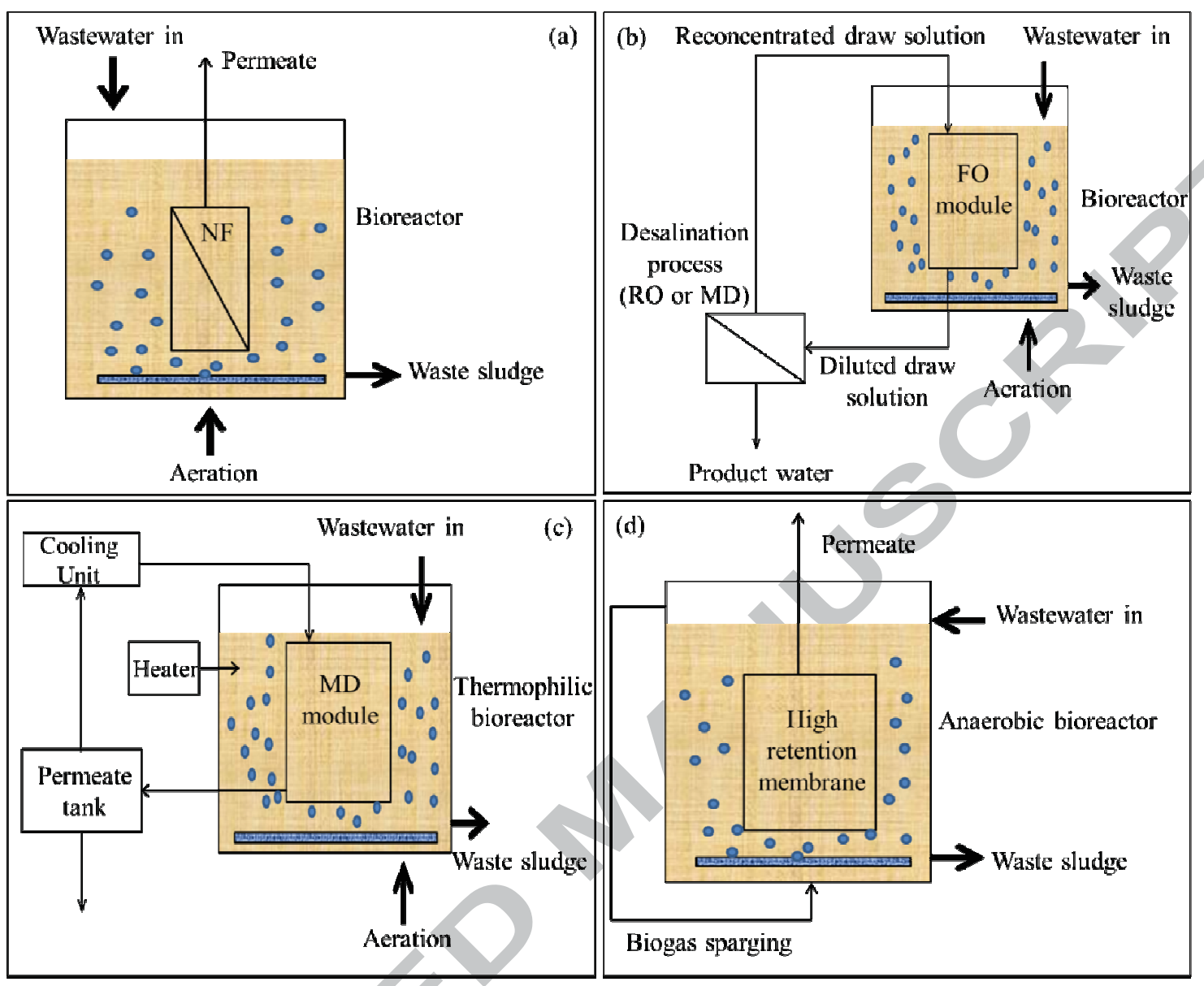

Fig. 1 


\begin{tabular}{|l|l|l|}
\hline \multicolumn{1}{|c|}{ Causes } \\
\hline $\begin{array}{l}\text { - Salts accumulation } \\
\text { - Reverse salt flux (OMBR) }\end{array}$
\end{tabular}

Fig. 2 


\section{LIST OF TABLES}

Table 1: Key differences between conventional MBRs and HR-MBRs.

\begin{tabular}{|c|c|c|c|c|}
\hline Characteristics & Conventional MBRs & \multicolumn{3}{|c|}{ HR-MBRs } \\
\hline Type & MF/UF-MBR & NF-MBR & OMBR & MDBR \\
\hline Membrane & $\begin{array}{l}\text { Hydrophilic } \\
\text { MF/UF }\end{array}$ & $\mathrm{NF}$ & FO & $\begin{array}{c}\text { Porous hydrophobic } \\
\text { MF }\end{array}$ \\
\hline Driving force & $\begin{array}{l}\text { Hydraulic } \\
\text { pressure }\end{array}$ & $\begin{array}{l}\text { Hydraulic } \\
\text { pressure }\end{array}$ & $\begin{array}{l}\text { Osmotic } \\
\text { pressure }\end{array}$ & Vapour pressure \\
\hline $\mathrm{NaCl}$ rejection $(\%)$ & Negligible & $40-90^{b}$ & $\sim 100^{\mathrm{d}}$ & \\
\hline $\begin{array}{c}\text { TOC in permeate } \\
(\mathrm{mg} / \mathrm{L})\end{array}$ & $3-10^{a}$ & $1-4^{b}$ & $<3^{\mathrm{e}}$ & \\
\hline Water flux $\left(\mathrm{L} / \mathrm{m}^{2} \mathrm{~h}\right)$ & $10-30^{\mathrm{a}}$ & $<2.5^{\mathrm{b}, \mathrm{c}}$ & $<10^{\mathrm{e}}$ & $2-15^{\mathrm{f}, \mathrm{g}}$ \\
\hline
\end{tabular}

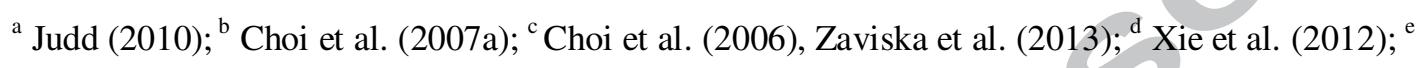

Achilli et al. (2009), Cornelissen et al. (2011), Zhang et al. (2012a), Alturki et al. (2012), Lay et al.

(2011), Qiu and Ting (2013), Wang et al. (2014); ${ }^{\mathrm{f}}$ Phattaranawik et al. (2008), Khaing et al. (2010); ${ }^{\mathrm{g}}$

Goh et al. (2013), Wijekoon et al. (2014a). 
Table 2: Organic and nutrient removal by HR-MBRs.

\begin{tabular}{|c|c|c|c|c|c|c|}
\hline \multirow{2}{*}{ Types } & \multirow{2}{*}{ Wastewater matrix } & \multicolumn{4}{|c|}{ Removal efficiency (\%) } & \multirow{2}{*}{ Ref. } \\
\hline & & TOC & COD & $\mathrm{NH}_{4}^{+}-\mathrm{N}$ & $\mathrm{TP}$ & \\
\hline \multirow{3}{*}{ MDBR } & Petrochemical & 96.5 & -- & $>96$ & -- & Khaing et al. (2010) \\
\hline & Synthetic & 99.9 & -- & $>98$ & -- & Phattaranawik et al. (2009) \\
\hline & Synthetic & $>99$ & -- & -- & -- & Wijekoon et al. (2014a) \\
\hline \multirow{6}{*}{ NF-MBR } & Synthetic & $>95$ & -- & -- & $\overline{--}$ & Choi et al. (2002) \\
\hline & Synthetic & $>95$ & -- & $>90$ & -- & Choi et al. (2006) \\
\hline & Domestic wastewater & $>91$ & -- & -- & -- & Choi et al. (2007a) \\
\hline & Domestic wastewater & $>95$ & -- & $>88.5$ & -- & Choi et al. (2007b) \\
\hline & Synthetic & -- & 95 & -- & -- & Zaviska et al. (2013) \\
\hline & Hospital wastewater & -- & 92 & $>70$ & 68 & Kootenaei et al. (2014) \\
\hline \multirow{4}{*}{ OMBR } & Synthetic & 99 & $\begin{array}{l}- \\
-\end{array}$ & $>96$ & -- & Achilli et al. (2009) \\
\hline & Synthetic & $>99$ & -- & -- & & Lay et al. (2012) \\
\hline & Synthetic & -- & 99 & 99 & & Qiu and Ting (2013) \\
\hline & Synthetic & $>98$ & -- & $>98$ & - & Tan et al. (2014) \\
\hline$\underset{\mathrm{a}}{\mathrm{AnOMBR}}$ & Synthetic & -- & 96 & $60-80$ & 100 & Chen et al. (2014) \\
\hline
\end{tabular}

${ }^{a}$ AnOMBR: anaerobic osmotic membrane bioreactor. 
Table 3: Examples of TrOC rejections by high retention membrane processes.

\begin{tabular}{|c|c|c|c|c|c|c|}
\hline \multirow{2}{*}{ Compounds } & \multirow{2}{*}{$\begin{array}{l}\text { Molecular weight } \\
(\mathrm{g} / \mathrm{mol})^{\mathrm{a}}\end{array}$} & \multirow{2}{*}{$\begin{array}{c}\log D \\
\text { at } \mathrm{pH} 8^{\text {a }}\end{array}$} & \multirow{2}{*}{$\begin{array}{c}\quad \mathrm{pK}_{\mathrm{H}} \\
\text { at } \mathrm{pH} 8^{\text {a }}\end{array}$} & \multicolumn{3}{|c|}{ Rejection (\%) } \\
\hline & & & & $\mathrm{NF}^{\mathrm{b}}$ & $\mathrm{FO}^{\mathrm{c}}$ & $\mathrm{MD}^{\mathrm{d}}$ \\
\hline Ibuprofen & 206.3 & 0.14 & 10.06 & $30-100$ & $>80$ & $>98$ \\
\hline Naproxen & 230.3 & -0.18 & 12.12 & $>95$ & $80-93$ & 100 \\
\hline Fenoprop & 269.51 & -0.28 & 11.46 & -- & $>95$ & $>98$ \\
\hline Gemfibrozil & 250.3 & 1.18 & 11.61 & $>95$ & $70-95$ & -- \\
\hline Ketoprofen & 269.51 & -0.28 & 6.18 & $>95$ & $>95$ & $>98$ \\
\hline Triclosan & 289.54 & 4.12 & 5.37 & $30-90$ & $>95$ & \\
\hline Diclofenac & 296.15 & 1.06 & 11.29 & $>90$ & $>95$ & - \\
\hline Sulfamethoxazole & 253.28 & -0.96 & 13.09 & $0-100$ & $90-98.2$ & -- \\
\hline Carbamazepine & 236.27 & 1.89 & 9.79 & $10-100$ & $50-97$ & $>95$ \\
\hline Primidone & 218.25 & 0.83 & 13.93 & $>90$ & $80-90$ & 100 \\
\hline Caffeine & 194.19 & -0.63 & 13.40 & $70-80$ & $50-90$ & -- \\
\hline Bezafibrate & 361.82 & -1.2 & 18.96 & $>80$ & $>80$ & -- \\
\hline Acetaminophen & 151.16 & 0.47 & 10.72 & $5-40$ & $40-50$ & -- \\
\hline Bisphenol A & 228.29 & 3.64 & 8.65 & $21-99.9$ & $>80$ & $>95$ \\
\hline $\begin{array}{l}17 \alpha- \\
\text { ethynilestradiol }\end{array}$ & 296.48 & 4.11 & 9.02 & $80-90$ & $80-95$ & 97 \\
\hline $17 \beta$-Estradiol & 272.38 & 4.14 & 8.67 & $70-90$ & $80-90$ & 98 \\
\hline Estriol & 288.38 & 2.53 & 10.76 & $80-99$ & $60-90$ & 100 \\
\hline 4-tert-octylphenol & 150.22 & 3.39 & 5.12 & $42-95$ & -- & 54 \\
\hline Atrazine & 215.68 & 2.64 & 7.28 & $80-90$ & $40-90$ & 99 \\
\hline
\end{tabular}

a The $\mathrm{pK}_{\mathrm{H}}$ value is defined as $\mathrm{pK}_{\mathrm{H}}=-\log _{10} \mathrm{H}$. $\mathrm{H}$ is the Henry's law constant value which was calculated as: Henry's law constant at $25^{\circ} \mathrm{C}\left(\right.$ atm. $\left.\mathrm{m}^{3} / \mathrm{mol}\right)=$ Vapour pressure $\times$ molecular weight $/$ water solubility. Molecular weight, $\log D$, vapour pressure and water solubility values were from Scifinder Scholar.

${ }^{\mathrm{b}}$ Kimura et al. (2003), Nghiem and Hawkes (2007); Yoon et al. (2007); Simon et al. (2009).

${ }^{c}$ Valladares Linares et al. (2011); Xie et al. (2012); Alturki et al. (2013).

${ }^{\mathrm{d}}$ Wijekoon et al. (2014b). 
Table 4: Performance of biological treatment of wastewater under saline condition.

\begin{tabular}{|c|c|c|c|c|c|}
\hline \multirow{2}{*}{ Wastewater matrix } & \multirow{2}{*}{$\begin{array}{l}\text { Salinity } \\
(\mathrm{g} / \mathrm{L} \mathrm{NaCl})\end{array}$} & \multirow{2}{*}{ Bioreactor type } & \multicolumn{2}{|c|}{$\begin{array}{c}\text { Removal } \\
\text { efficiency }(\%)\end{array}$} & \multirow{2}{*}{ Ref. } \\
\hline & & & COD & $\mathrm{TKN}^{\mathrm{a}}$ & \\
\hline Tannery soak liquor & $21-57$ & $\mathrm{SBR}^{\mathrm{b}}$ & 95 & 96 & $\begin{array}{l}\text { Lefebvre et } \\
\text { al. }(2005)\end{array}$ \\
\hline Meat industry wastewater & $50-200$ & SBR & $>90$ & $20-30$ & $\begin{array}{c}\text { Alvaro et al. } \\
(2009)\end{array}$ \\
\hline Saline synthetic wastewater & $30-72$ & $\begin{array}{l}\text { Aerobic } \\
\text { bioreactor }\end{array}$ & $88-94$ & & $\begin{array}{l}\text { Abou Elela et } \\
\text { al. (2010) }\end{array}$ \\
\hline $\begin{array}{c}\text { Hypersaline synthetic } \\
\text { wastewater }\end{array}$ & $110-130$ & $\mathrm{IABF}^{\mathrm{c}}$ & 63.1 & & $\begin{array}{l}\text { Shi et al. } \\
\text { (2012) }\end{array}$ \\
\hline $\begin{array}{l}\text { Pickled plum production } \\
\text { wastewater }\end{array}$ & 150 & Aeration tank & & & $\begin{array}{l}\text { Kubo et al. } \\
\text { (2001) }\end{array}$ \\
\hline $\begin{array}{l}\text { Hypersaline synthetic } \\
\text { wastewater }\end{array}$ & 71.2 & MBR & & -- & $\begin{array}{c}\text { Sharghi and } \\
\text { Bonakdarpour } \\
(2013)\end{array}$ \\
\hline
\end{tabular}

${ }^{a}$ TKN: total Kjeldahl nitrogen; ${ }^{b}$ SBR: Sequencing batch reactor; ${ }^{b}$ IABF: intermittently aerated biological filter. 


\section{RESEARCH HIGHLIGHTS}

- HR-MBR integrates high rejection membrane and biological treatment in a single step

- HR-MBR is compact and can offer high treatment capacity suitable for water reuse

○ Salinity buildup, low flux, membrane stability must be addressed in future research

- Possible directions to address these challenges were suggested 